Brailas, A. (2021). Digital storytelling and the narrative turn in psychology: Creating spaces for collective empowerment. Global Journal of Community Psychology Practice, 12(4), 1 - 19.

\title{
Digital storytelling and the narrative turn in psychology: Creating spaces for collective empowerment
}

Alexios Brailas

\begin{abstract}
In this article, we propose a model that combines digital storytelling with narrative practice to create a facilitated peer-to-peer experiential learning space for collective empowerment. This model was inspired by an educational intervention that utilized participatory digital comic strip making to raise students' awareness of bullying and its consequences. The makerspace involved allows for the creation of digital artifacts representing participants' personal narratives. Narrative practice is grounded in the idea that there are no problematic people but rather not effective narratives about how people are supposed to act. Making digital stories, getting constructive peers feedback, and then releasing more polyphonic and adaptive sequel versions is proposed here as an effective way to raise participants' awareness and help them integrate different points of view, as well as enrich their narratives on critical social phenomena. A significant advantage of the digital storytelling genre employed is that the digital artifacts produced have a concrete material presence: they can be shared, performed, or modified. Participants, with the help of their peers, participate in a group process facilitated by their teacher, aiming to locate and change problematic elements in their stories, and by doing so they materialize and consolidate the improvement in their personal narratives.
\end{abstract}

Keywords: narrative inquiry; peer-to-peer learning; digital storytelling; community practice; comics; group work; empowerment; resilience; bullying

\section{Introduction}

In recent years creative research methods that utilize multimodal artifacts are used more and more in educational research and practice (Mannay, 2015). The inclusion of non-verbal modalities in a community project allows participants to access and communicate their lived experiences in a radically new way (Brailas, 2020b; Vakali \& Brailas, 2018). A digital story is any multimodal digital artifact that can be experienced offline or online and serves a specific aim, communicates a message, tells a story, by utilizing more than one modality (Brailas, 2017; Kress, 2010; Tham, 2015). Digital stories can take the form of a cloud document, video, comic book, presentation, blog, or any other possible digital format. Today, digital stories can 
be produced easily by anyone without the need for special technical skills by using a plethora of software tools or web services. Modern teens constantly interact with digital tools and participate in the social reality around them by producing DIY (Do It Yourself) story-artifacts (Brailas \& Tsekeris, 2014). Such stories are experienced online or face-to-face while influencing participants' lives in both their physical and digital realities (Tzanavaris et al., 2021). In this article, we treat digital storytelling, the process of developing and sharing digital stories with a real or an imagined audience, as an intermediate between the representational and the performative end (Brailas, 2020b). People interact with their digital creations during their development as well as during their distribution and sharing, either synchronously or asynchronously. By doing so, storytellers create formal or informal spaces of collaborative learning. Participants contribute to an emerging transformative practice, through iterative cycles of reciprocal determination: "We act in the world, and the world acts on us, to and fro, in a dynamic process I call the 'dance of agency', in which all the partners are unpredictably and emergently transformed." (Pickering, 2017, p. 136)

In this paper, we propose a coherent model for educational interventions that combines digital storytelling with narrative practice to create facilitated peer-to-peer spaces for collaborative learning and collective empowerment. This model was developed based on an educational intervention in which digital storytelling, in the form of creating comic strips, provided a group of students with the opportunity to explore and reauthor dysfunctional elements of their bullying narratives. Narrative practice promotes the idea that there are no problematic people but rather dysfunctional personal constructions, or cognitive schemata, about how people are supposed to act in specific situations (Dickerson, 2016; Ricks et al., 2014; White, 2007). Cultural narratives have impact on people and determine their social behavior (Denzin, 2001). Personal narratives matter: "These narratives possess the capacity to inhibit an individual's growth and happiness, or can empower and enable wellbeing and contentment" (Casares \& Gladding, 2019, p. 3). The task of a narrative practitioner in a group of participants is to explore the dominant stories (Casares \& Gladding, 2019) and unearth the neglected narratives that influence human behavior, consciously or unconsciously (Lessard et al., 2018). The digital storytelling makerspace described in this article allows for the creation of self-exploratory digital artifacts that represent personal narratives and uncover the group dynamics. Digital storytelling can be utilized to access, externalize and share personal narratives: "Group brainstorming and discussion of story topics can raise previously unacknowledged situations and behaviors to the surface and provide a forum for open exploration, discourse, and hopefully clarification of appropriate behaviors and actions" (Sawyer \& Willis, 2011, p. 276). Especially when the environment is appreciative, "the relating of personal stories to interested listeners ... can provide the foundation for the development of resilience" (East et al., 2010, p. 23). Digital storytelling in educational interventions supports 
young people's ability to reflect on their lives, learn from their peers, focus on the positive aspects, and identify best working scenarios for their lives (De Vecchi et al., 2016).

\section{Narrative inquiry and digital media in education}

Narrative inquiry and digital storytelling can play a critical role in creating educational spaces for peer support, connection, and encouragement. Storytelling offers opportunities for students to recreate the narratives by which they live. Stories provide individuals "the power to see possibilities by telling variations of a story about themselves and their lives, opening the possibility to live by these alternative narratives" (Staley, 2018, p. 24), therefore, creating alternative futures and more appreciative spaces to live in. As McAdam and Lang (2003) point out, "We see language not only as describing but as creating and doing... the language we use creates our worlds. Language has the power to move us to laughter, to bring us to tears, to lead us to feel with others in their lives." (p. 49) Digital storytelling can provide a safe collaborative space to discuss issues of identity and positionality, to address stigmatized topics, and to listen to marginalized voices (Gachago \& Livingston, 2020; Guse et al., 2013; Matthews \& Sunderland, 2017). Group storytelling enables participants to interrogate and address prior trauma, support each other, and re-author stigmatizing conversations (Gubrium

et al., 2019). Stories bear the potential to convey critical messages and effectively communicate different perspectives. Stories can "evoke feelings, create empathy, trigger tears, and arouse rage. They provide frameworks for finding meaning in lives and the world. And they can help shape beliefs and actions that are inclusive and supporting or exclusive and destructive." (Glesne \& Pugach, 2018, p. 31)

Digital storytelling has been widely used in educational settings to explore bullying narratives. Digital storytelling can inform students about bullying and help them grasp the difficult emotions that bullied students experience (Fokides, 2016, 2017). In a research project by Thompson (2014) students who engaged in collaborative digital storytelling demonstrated a notable increase in their levels of empathy toward the bullied as well as toward the bullies and the bystanders. In another research study, digital storytelling was used to situate students in specific bullying scenarios and make explicit to them the cognitive and emotional patterns involved (Tsai et al., 2011). Digital storytelling can be used as a creative counseling and therapeutic tool to positively influence the behavior of children and adolescents (Sawyer $\&$ Willis, 2011). Collaboratively authoring digital stories at school can create an engaging and rewarding environment where teachers can organize specific tasks and students feel that they are in charge of the learning process (Blas et al., 2010). Digital storytelling can also be used to address health inequities by using technology to unearth the voices of vulnerable groups and underrepresented communities, and by helping participants to reflect on their difficult 
experiences and seek support (Briant et al., 2016).

Glesne and Pugach (2018) systematically asked their students, undergraduates in teacher education courses, to share stories and listen to the stories of others. Their narrative and social constructionist practice focused on students sharing autobiographical stories with pairs of different cultural-historical backgrounds, for example asking white students to work with Black, Latino, Hmong, or Native American students. This allowed for the difference that makes the difference in Bateson's words; students were able to enrich their perspectives and become more polyphonic in their own narratives: "these story-featuring learning opportunities were designed specifically to create empathy and disrupt students' (often negative or stereotypical) views" (p. 35).

The diverse modalities employed in digital storytelling offer simultaneous access to multiple levels of cognitive processing (informational, emotional, or cultural) (Alonso et al., 2013). Collective spaces for narrative practice help participants enrich their personal stories by acknowledging and integrating multiple perspectives: "narrative techniques created a sense of empathy and understanding among our students for individuals and communities with differing life circumstances. Students made personal connections to and grew curious about and interested in people, cultures, or situations" (Glesne \& Pugach, 2018, p. 37).

\section{Creating facilitated peer-to-peer learning spaces for collective empowerment}

Many terms have been used before to describe a systemic, networked apprehension of learning: bottom-up pedagogy, rhizomatic learning, peer-to-peer learning, communities of practice, learning organizations, connectivism (Brailas, Koskinas, et al., 2017; Brailas, 2020b). All these terms represent a new understanding of learning as an emergent group phenomenon. This is a perspective that locates learning not only in each and every individual, but (as well) in their collective power: what the group as a whole is able to perform and achieve. Toward this direction, Dave Cormier (2008) coined the term Rhizomatic Learning to describe a peer-to-peer learning ecology, being inspired by the seminal work of Deleuze and Guattari, and in a global context of exponential growth of the social networking sites.

Deleuze and Guattari (1987) defined the rhizome as an acentric multiplicity, something that "has no beginning or end; it is always in the middle, between things, interbeing, intermezzo. Proceeding from the middle, through the middle, coming and going rather than starting and finishing" (p. 25). This conception of the philosophical rhizome shares common characteristics with the botanical original and resembles to the organizational principle of the Internet as a network of networks with no central hub needed for its operation.

The learning rhizome is a wonderful metaphor to realize the dynamic nature of a peer-to- 
peer space for collective empowerment. In this view, learning can be defined as "the process of extending, nurturing, cultivating, and catalyzing the development of a living network, consisting of knowledgeable agents, both human and artificial, and material objects/resources." (Brailas, 2020b, p. 310). These material objects/resources can take the form of digital stories in a storytelling project. As digital bricoleurs (Sherman \& Briggs, 2020), participants can utilize the resources available in their networks to enhance their narratives. But this is not a matter of mere summing resources and actors. This is about creating a space of dense group interactions and meaningful synergies that add extra value by processing and integrating the different perspectives of the participants. As Michael Bakhtin argues, "You can see things behind my back that I cannot see, and I can see things behind your back that are denied to your vision ... although we are in the same event, that event is different for each of us." (page 22). In every synergy, in every interaction between two actors, there are three entities: actor one, actor two, and their relation adding extra value.

Capra and Luisi (2014) point out that the network pattern is the very fundamental pattern of life. But the network as a dynamic process not as a static structure. That is what makes rhizome (both the botanical original and the philosophical one) a wonderful metaphor for learning: rhizomes are always in the becoming, always developing toward every possible direction in a nomadic way. In this context, learners can be understood as nomads traversing their personal learning networks in their own ways in the context of a community of colearners, and, by doing so, they co-create wonderful and unique peer-to-peer collectives (Brailas, 2020b).

In rhizomatic education, the primary role of the educator is not to share her wisdom as in the sage on the stage archetype, but rather to catalyze and facilitate the development of the peer learning network, a coherent learning group, an acentric multiplicity with emergent properties. As a guide in the side (King, 1993) teacher will indirectly drive learning toward collective empowerment: "the rhizome creates the background, the contextual validity, and the situated meaning for individual actions ... By developing learning rhizomes, selforganizing confluences of human and nonhuman in the becoming, we participate in anotropic performative dances which help us unfold our full living potential." (Brailas, 2020b, p. 313) The teacher as facilitator in a peer-to-peer learning process for collective empowerment has the duty to develop a space where the participants will be able to cocreate "alternative connections, new networks of thinking, and new patterns of relating with each other, and with other available human nodes or non-human learning resources ... The rhizome as a whole becomes the teaching apparatus, a multiplier of perspectives, and an amplifier of synergies." (Brailas, 2020b, p. 310) 


\section{The Comics to Stop Bullying project}

The Comics to Stop Bullying project was a focused school intervention, a makerspace for cocreating digital stories, aiming to raise students' awareness of bullying and its consequences. The project took place in a public high school in Athens, Greece, during February 2016. The intervention was designed and implemented by the author, who was at that time in charge of the school's bullying prevention program. Twenty-one students participated in the project that lasted for two months. By using digital comic strip production tools, students were able to communicate their stories effectively through a sequence of images supplemented with text bubbles. Comic strips are inherently multimodal, combining narrative and visual elements, and can serve as a provocative research instrument to engender deep reflection among participants (LeBlank \& Irwin, 2018). Many digital comic strip production tools are available online, allowing anyone to create professional-looking products without the need to be graphic artists themselves. These applications allow users to set the comic strip background by selecting predefined patterns, to drag and drop characters onto the backgrounds, and to add text bubbles (Brailas, 2017). In this particular intervention, students utilized StoryboardThat (http://storyboardthat.com), a freemium online comic strip creation platform with a simple-to-use interface and a short learning curve. An open-source alternative tool recently developed is ComigGen library (https://gramener.com/comicgen). Comicgen was used to create the example comic-strip stories (under cc0 licenses) used in this article to demonstrate the narrative re-authoring practice (in Figures 2 and 3). When possible, we suggest educators utilize open-source tools and open-licensed materials to avoid copyright infringements, and to contribute to the educational commons and the democratization of educational systems (Pechtelidis \& Kioupkiolis, 2020).

Students were placed in small groups to create a six-cell digital comic strip story about bullying, based on their own experiences, thoughts, and feelings (Figure 1). A project blog was used as a hub to aggregate the students' comic strip artifacts and make these available to the entire group out of the classroom. The comic strip artifacts provided the author with an opportunity to understand students' representations of bullying and to identify potential problematic elements in their narratives. Many of the students' stories reproduced stereotypes and dominant narratives related to bullying. The first versions of the digital comics then served as triggers to initiate whole group discussion of the situations depicted in each small group's story. The researcher helped the whole group to focus on the weaknesses and strengths of each story, and make suggestions for changes and/or additions, creating a facilitated peer-to-peer learning environment. Then the student groups were invited to redesign 'sequel' stories: improved and more functional versions of their first comic strips based on the feedback they got from their peers. The intervention concluded with a presentation of the final artifacts produced to the whole group. 
After the intervention, polytextual thematic analysis (Gleeson, 2011; Silver, 2013) was used to investigate the students' initial and sequel comic strip stories and identify themes within these narratives about bullying. Central themes that emerged across the two versions of the stories were: the fragile bully, the automatic teacher reactions (e.g., expelling from class), the different other as a trigger for bullying, the safety net that friends offer, and the critical role that social media play in bullying. In the initial stories, more dominant were the patterns of the lonely victim, the lonely bully, the only watching bystander, the only punishing teacher. In the sequel stories, the patterns that more often emerged were family and community involvement, emotional empathy, friends offering help, and managing reconciliation.

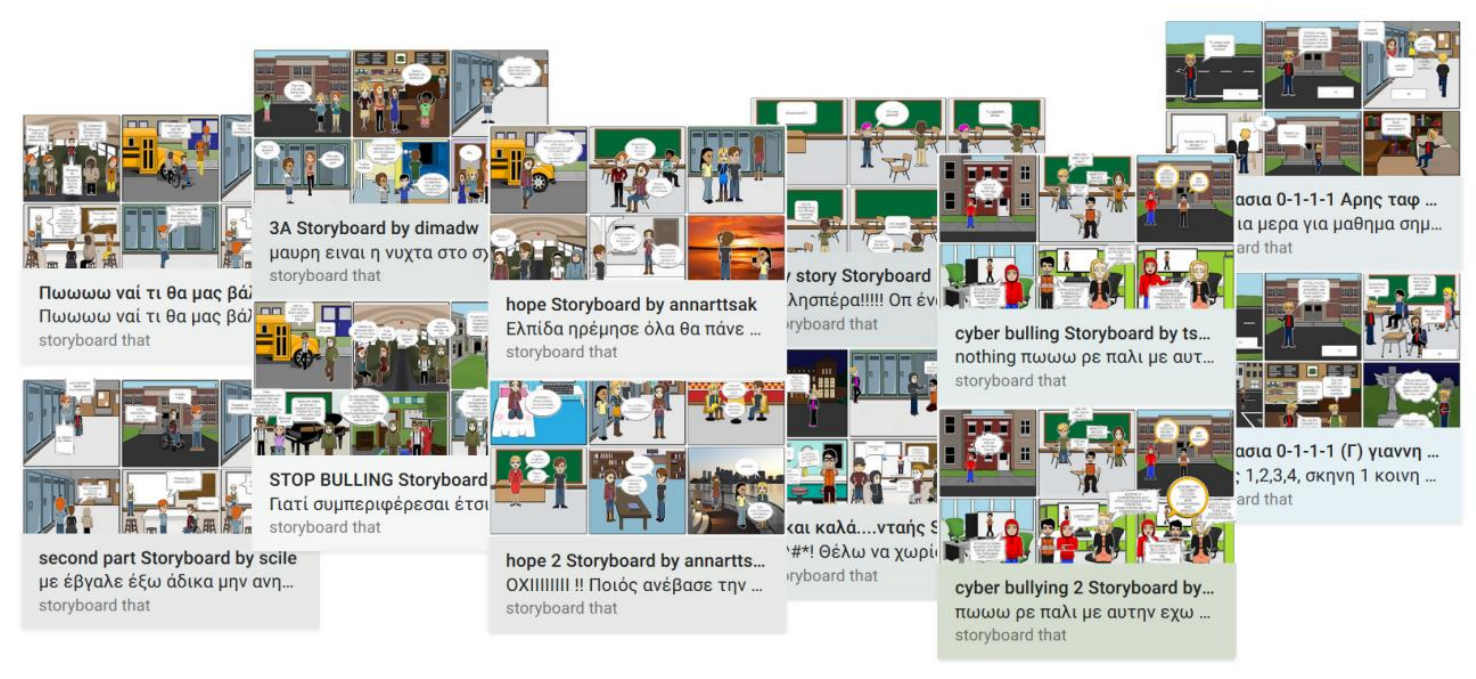

Figure 1. Six double-versioned comics were created by the students during this intervention. Each version consisted of a six-cell comic strip. The comics provided a multimodal way to explore and reauthor problematic narratives.

\section{Using the case study to develop a model}

In the present study, we adopted a qualitative case study approach combined with narrative inquiry. The qualitative case study "facilitates exploration of a phenomenon within its context" (Baxter \& Jack, 2008, p. 544). The aim of our exploration was not merely to document the intervention, but rather "to use empirical data to gain insight into some broader set of social phenomena than those provided by the data themselves" (Livesey \& Runeson, 2018, p. 43). The ultimate aim was to build a concise theoretical model based on that particular case that would inform future practice, as "research that produces nothing but books will not suffice" (Lewin, 1946, p. 35). Although a situated rich description of an educational intervention provides invaluable insights into a social situation, it cannot be verified or falsified out of its context. However, theoretical models that emerge from such 
interventions can be tested and subjected to further rigorous investigation in the future. In the present study, the process involved narrative inquiry by gathering data from the participants' digital storytelling artifacts. As Leavy (2015) argues, "narrative inquiry or the narrative method attempts to collaboratively access participants' life experiences and engage in a process of storying and re-storying in order to reveal multidimensional meanings and present an authentic and compelling rendering of the data" (p. 47). In the next sections, based on our experience of the Comics to Stop Bullying project, we will attempt to combine digital storytelling with narrative practice into a coherent theoretical model for use in educational and/or community interventions.
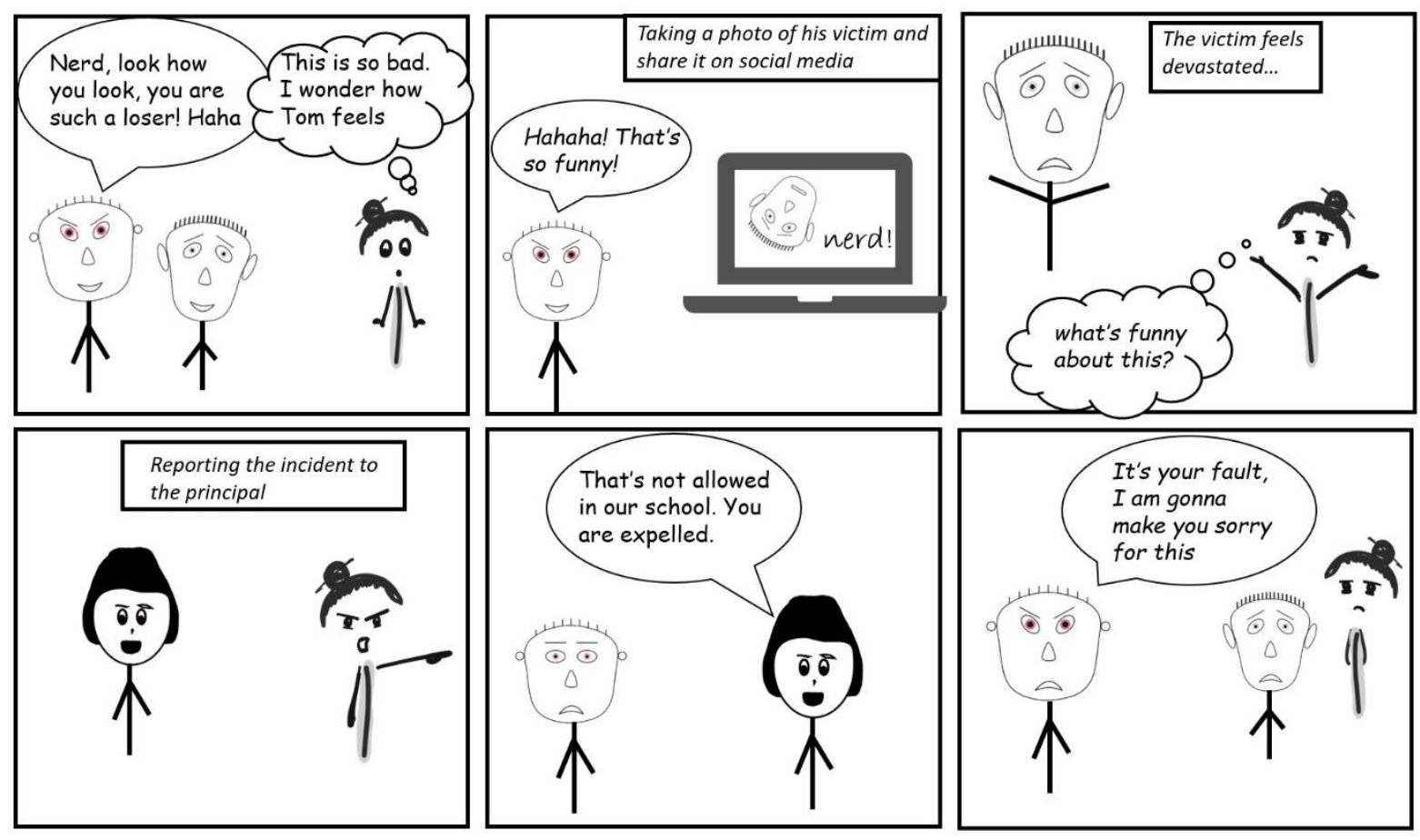

Figure 2. A typical scenario of an initial comic-strip version representing a dysfunctional bullying narrative. The voices of the actors involved do not acknowledge different points of view, neither show empathy for others' feelings.

\section{Empowering and life-promoting narratives}

A personal narrative regarding a specific problematic situation should be regarded as functional in the broader sense when that narrative can help the individual and the community prevent or overcome the problematic situation. The relative literature on bullying indicates many critical factors for effective prevention like peer-support for victims, encouraging help-seeking, social-emotional learning and training for both teachers and 
students, intensive social skills training, dedicated school meetings and training for parents, highlighting the importance of the bystanders' behavior, informing and engaging the families, holding regular classroom meetings on the topic, seeking for the help of mental health workers, and fostering a family-school-community empowering alliance (Albrecht, 2021; Bradshaw, 2015; Farrington \& Ttofi, 2009; Lester et al., 2017; Olweus \& Limber, 2010; Villarejo-Carballido et al., 2019). School interventions seem to be more effective and efficiently, and can change the school culture "when they include the entire school, when they use a social skills promotion model, when they include peer education, when they favour student participation and initiative, when they use interactive and participated methodologies, and when they last several years" (Tomé et al., 2021, p. 21). The proverb goes as "It takes a village to raise a child". Based on the existing literature we can suggest that it takes a whole community to prevent bullying.
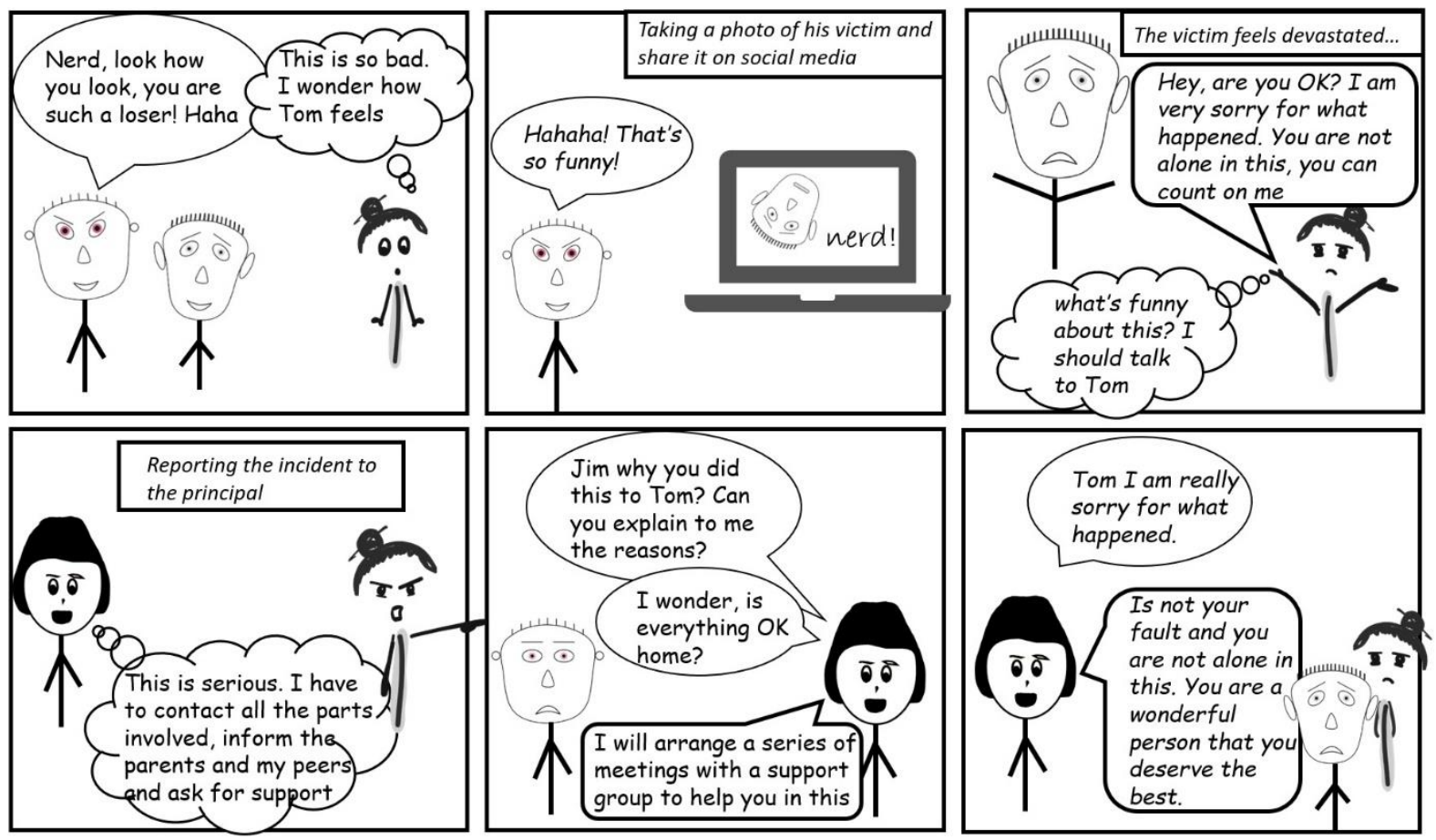

Figure 3. A typical scenario of a revised comic-strip version representing a more functional narrative.

For an example of a dysfunctional bullying narrative, as depicted in a digital story, consider the comic strip in figure 2. In this hypothetical scenario, the feelings of the people involved are not shared or acknowledged. The story is presented as an automatic and inescapable sequence of events: bullying incident, followed by reporting the incident, and punishing the bully. Students are presented as living in a void, without a supporting network such as family, friends, or the school community. No empathetic dialogue and sharing of feelings take place 
between the students, or between the students and the teacher. The punishment from the authority figure comes as an automatic response to the incident, without explaining the rationale behind and without trying to explore and understand the bully's context and cognitive schemata that led him to bully his classmate. No care is taken to emotionally support the victim, the bully, and the bystander, and there is no action taken to avoid recurring of problematic behavior.

A more functional digital story that helps prevent bullying should include cooperation between families, teachers, and the school community (Limper, 2000) as the one presented in figure 3. In this version of the story, there is a greater concern expressed to understand the special circumstances and the feelings of all the parties involved. A determination to call the whole school community to be part of the solution. The participants in the story demonstrate increased empathy.

\section{Modeling the process: A step-by-step guide for educational interventions}

"We don't know what we mean until we see what we say" (Blachowicz, 1998, p. 356).

\section{Step 1: Tell a story through a digital artifact}

The theoretical model illustrated in Figure 4 follows the narrative turn in psychotherapy, which focuses on the idea that as people go through their lives they internalize and hold dominant stories and beliefs about the social phenomena around them (Carlson, 1997; Staley \& Freeman, 2017). These stories are influenced by personal experiences as well as by social stereotypes and dominant public discourses. A primary goal of the proposed model is to help students externalize their personal narratives about a social phenomenon with the facilitation of a projective medium, such as digital storytelling. In this way, students' stories "can provide insights into their backgrounds and experiences, giving a greater understanding of them in context" (East et al., 2010, p. 2018). Visual enhanced methods can facilitate access to meanings, emotions, experiences, and stories that are not easily communicated otherwise (Kearney \& Hyle, 2004; Silver, 2013). Digital storytelling has the potential to make alternative knowledge more visible and actionable (Thompson Long \& Hall, 2018). By externalizing their stories, people become free to explore alternatives and to reauthor their narratives in a more empowering way (White, 1993). In the particular case discussed above, students were encouraged to work in small groups of two to four members and create a multimodal comic strip story about bullying. 


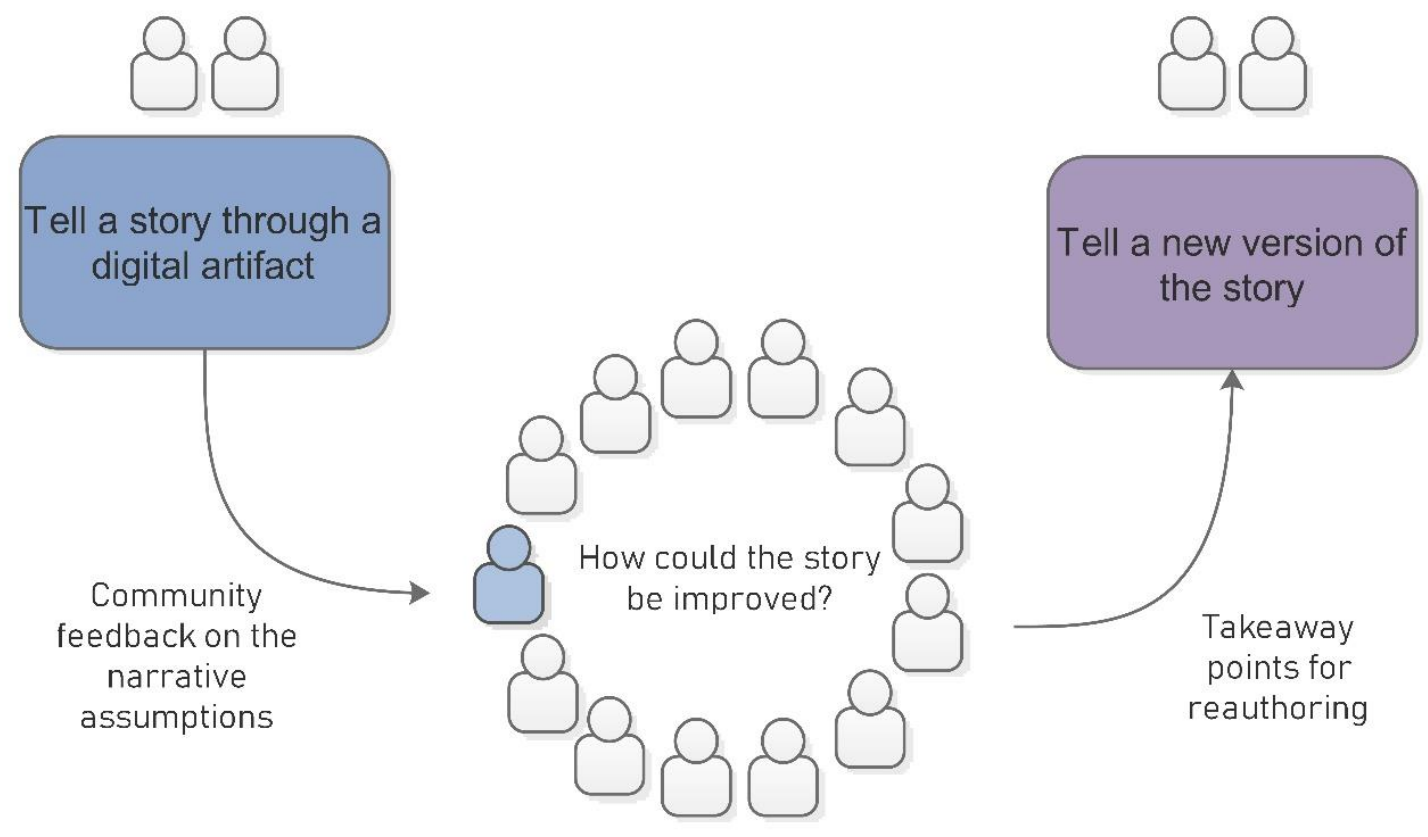

Figure 4. Digital storytelling, community feedback, and reauthoring to enrich personal narratives: A facilitated peer-to-peer learning makerspace for collective empowerment

\section{Step 2: How could the story be improved?}

The second phase of the proposed model begins with a teacher-facilitated peer-to-peer discussion, in which each group's comic strip is shared and discussed with the whole group in a storytelling circle. Students are invited "to reflect on their dominant stories and to begin to consider alternative narratives regarding their perceived deficits, problems, and challenges" (Casares \& Gladding, 2019, p. 6). Maladaptive points, dysfunctional narratives, and not wellworking scenarios are identified and get feedback from the whole group, with the help of the teacher when needed as a guide in the side of the group. Positive points, themes of resilience and empowerment, and best working practices are identified and acknowledged as well. The facilitator should invest in an appreciative culture that empowers members to express their thoughts in a constructive way (Brailas, Koskinas, et al., 2017; McAdam \& Lang, 2009). The aim is for the large group to provide a safe and supportive environment that facilitates meaningful communication (Beltran \& Begun, 2014; Polychroni et al., 2008). Such a context allows for deeper meaningful involvement in each story. The large group provides feedback to the small groups on the strengths and/or weaknesses of each story and possible ways to improve the initial versions. And this feedback does not originate from an authority figure, but it comes from the peers' network in a bottom-up ecology of learning. In this way, the 
comic strip stories become "constructed objects which foster dialogue and discussion. Fellow participants serve as critics to one another and provide valuable guidance as the story takes shape, acting as an in vitro audience" (Freidus \& Hlubinka, 2002, p. 1).

\section{Step 3: Tell a new version of the story}

Following the whole group discussion, students are instructed to reauthor the original stories to produce more adaptive versions, materializing the group feedback as sequel versions of the initial stories. A major advantage of the digital storytelling genre is that digital artifacts have a concrete material presence; they can be viewed, reviewed, shared face-to-face or online, performed and re-performed, modified, tinkered, tweaked, and fine-tuned. By locating specific problematic elements in their narratives, students can change specific points in the corresponding digital artifacts and quickly release new and more adaptive versions, or even create many alternative versions, compare them, and put them in a constructive dialogue. Co-constructing preferred versions of life in this way could have positive effects on building personal resilience and empowering communities (Dickerson, 2016; McAdam \& Lang, 2009).

\section{Discussion}

Through writing, sharing, and rewriting comic strip stories, students were provided with the opportunity to better realize the complex and multifaceted nature of bullying-related behaviors. Multimodal and embodied methods help make the complexity of lived experience more visible and tangible (Cahill et al., 2016). According to Fernandez \& Lina, "generating comic strips... can reveal dysfunctional cognitions that can consequently be addressed" (p. 1). Stories have the potential to "reveal the differences and similarities between people's experiences" (East et al., 2010, p. 17). De Vecchi et al. (2016) reported that: "Watching digital stories made by others and discussing them in a group supported young people to understand their experience of excessive alcohol consumption" (p. 190). However, reauthoring and enriching narratives has the potential to go beyond mere understanding, to be a transformative process, for the fact that "it is through our own narratives that we principally construct a version of ourselves in the world, and it is through its narrative that a culture provides models of identity and agency to its members" (Bruner, 1996, p. xiv).

This is about the enactment of a culturally responsive pedagogy that emphasizes critical knowledge production for a more inclusive learning environment (Rana \& Culbreath, 2019). Cultural meanings and socially constructed identities "can both support problems or help a person stand up to problems" (Stillman, 2016, p. 94). By changing our narratives, we change the world around us. Facilitated group discussions provide additional insight into 
participants' narratives allowing for local knowledge to emerge (Lichty et al., 2019). Through the group informed rewriting process, the digital stories can be enriched with new elements and support more empowering personal narratives, with the potential to build networks of resilience: "Elucidating personal stories involves sharing which can help form bonds and supportive networks. With reflection, these can help to develop resilience" (East et al., 2010, p. 17).

By sharing stories and empowering narratives, we can establish a more democratic classroom culture; a transformative community practice that promotes the development of autonomous human beings (Brailas, Avani, et al., 2017). An autonomy attained through and for interdependence (Vassiliou \& Vassiliou, 1982). Stories can create empowering and appreciative communities of inquiry: "These [narrative] strategies helped to build respect among participants, relationships, and sometimes, long-lasting friendships. By sharing their stories and the stories of others, students came to appreciate and value each other." (Glesne \& Pugach, 2018, p. 37) In the above context, the combination of digital storytelling, narrative inquiry, and facilitated peer-to-peer learning becomes a method that does not just represent the world; it carries the potential to transform and re-construct it in a performative way (Clark, 2017).

\section{Concluding thoughts}

The main contribution of the present study is that it combines digital storytelling and experiential learning and peer-to-peer facilitated group work and narrative/reflective practice to create a virtual makerspace of possibilities for personal growth and collective empowerment. While none of these practices mentioned is new, the combination of them seems to be quite powerful and promising. Digital storytelling is a form of learning by doing, learning by creating digital artifacts with a concrete material presence. These story artifacts represent personal narratives and the process of enhancing and enriching those personal narratives can be translated into a concrete tinkering process, the process of improving digital stories and releasing sequel versions. Sharing the stories in a group is a critical, humanizing, process: "sharing is not only an ethical or economic mandate, but a condition built into the structure of human perception, and thus a condition inherent in the very fact of being human." (Holquist, 2002, p. 34) The facilitated peer-to-peer interaction that follows offers a rich set of different perspectives and constructive feedback from the peers to be incorporated into the new story versions. In the virtual mirror that is created through the sharing of all the group stories, each participant can recognize her own unspoken voices and hidden narratives. This is "the tale of how I get my self from the other... In order to forge a self, I must do so from outside." (Holquist, 2002, p. 28) In other words, we co-author 
ourselves through the stories of our communities. But the main advantage of the group process is not just the informational and cognitive surplus that will enrich the stories and the personal narratives. It is through the peer-to-peer interactions that participants establish meaningful relationships among them, and it is through this process that they practice how to relate and connect with other human beings, and how to create personal humanizing networks. And this skill and attitude and mentality lies at the core of helping prevent bullying and empower a community: nurturing the ability to relate and connect with different human beings instead of isolating, scapegoating, and attacking. This interpersonal work is a prerequisite for promoting social-emotional learning and raising empathy (Brailas, 2020a; Goleman \& Senge, 2014). As Hessler and Lambert (2017) point out, "storytellers recognize one another as peers as they move through a shared creative struggle and culminating experience. The collaborative environment not only allows for the stories' communicative power to be considered and improved, but for a deeper level of communion to take place." (Hessler \& Lambert, 2017, pp. 26-27) For practical advice on how to facilitate enriching peerto-peer group work, by moving gradually from the individual to the whole-group level, see also: (Brailas et al., 2016; Brailas, Koskinas, et al., 2017).

Concluding this article, it is essential to highlight some of the limitations of this study. The proposed model for educational interventions combining digital storytelling, experiential learning, peer group work, and narrative inquiry was developed based on a one-time intervention with a small number of participants. There was no experimental design, and no pre and post measurement of participants' perceptions regarding bullying, to ensure that there was indeed a positive shift in their personal narratives regarding bullying. Therefore, this study lacks the ability to generalize. However, we need to emphasize that a positivist reductionist approach to research is not necessarily concerned with the creative application of a community practice to address the social challenges of the participants (Agner, 2021; Dafermos, 2018). The work presented here is a qualitative case study: a rigorous exploration of a phenomenon in context, aiming to develop a theoretical model (Baxter \& Jack, 2008) to inform community practice. The effectiveness of this model in quantitative terms needs to be supported by further research.

Notwithstanding these limitations, this paper makes a significant contribution by proposing a concise model for educational or/and community interventions that combines digital storytelling, narrative inquiry, and facilitated peer-to-peer work to create a space for collective empowerment. For participants to question implicit personal or social narratives, they need to be engaged in a collective inquiry led by facilitators who adopt an evocative, appreciative, and performative pedagogy in order to "engage children with alternative and subaltern identifications to create an expansive pedagogy in which each child can seek to find a place in the world and to imagine their lives otherwise." (O'Loughlin, 2016, pp. 19-20) 
Facilitated group feedback provides the context for new, more adaptive, personal narratives to emerge. Digital storytelling as a tinkering group process empowers participants to realize alternative, more polyphonic, ways of acting, thinking, and relating with each other. Participants create their digital stories, share them and get feedback, and then rewrite the stories more constructively, thus taking the first steps toward internalizing more positive narratives and more confident interactions with the world outside themselves. In this direction, storytelling and peer-to-peer work in the context of an appreciative community of inquiry becomes an emancipatory practice, a form of social activism.

\section{References}

Agner, J. (2021). Community Psychology Values and Community-Based Participatory Research. Global Journal of Community Psychology Practice, 12(1), 1-10.

Albrecht, D. (2021). The journey from traditional parent involvement to an alliance for empowerment: A paradigm shift. Theory Into Practice, 601), 7-17. https://doi.org/10.1080/00405841.2020.1827897

Alonso, I., Molina Plaza, S., \& Requejo, M. D. P. (2013). Multimodal digital storytelling: Integrating information, emotion and social cognition. Review of Cognitive Linguistics, 11(2), 369-387. https://doi.org/10.1075/rcl.11.2.10alo

Baxter, P., \& Jack, S. (2008). Qualitative Case Study Methodology: Study Design and Implementation for Novice Researchers. The Qualitative Report, 13(4), 544-559.

Beltran, R., \& Begun, S. (2014). "It is Medicine": Narratives of Healing from the Aotearoa Digital Storytelling as Indigenous Media Project (ADSIMP). Psychology \& Developing Societies, 26(2), 155-179. https://doi.org/10.1177/0971333614549137

Blachowicz, J. (1998). Of Two Minds: The Nature of Inquiry. State University of New York Press.

Blas, N. D., Paolini, P., \& Sabiescu, A. (2010). Collective digital storytelling at school as a whole-class interaction. Proceedings of the 9th International Conference on Interaction Design and Children, 11-19.

Bradshaw, C. P. (2015). Translating research to practice in bullying prevention. American Psychologist, 704), 322-332. https://doi.org/10.1037/a0039114

Brailas, A. (2017). Digital storytelling in the classroom: How to tell students to tell a story. International Journal of Teaching and Case Studies, 8(1), 16-28. https://doi.org/10.1504/IJTCS.2017.084407 
Brailas, A. (2020a). A Systems Thinking Approach to Reflective Practice in Blogs: Implications on Social-Emotional Learning and Resilience Building. Eighth International Conference on Technological Ecosystems for Enhancing Multiculturality, 304-308. https://doi.org/10.1145/3434780.3436564

Brailas, A. (2020b). Rhizomatic Learning in Action: A Virtual Exposition for Demonstrating Learning Rhizomes. Eighth International Conference on Technological Ecosystems for Enhancing Multiculturality, 309-314. https://doi.org/10.1145/3434780.3436565

Brailas, A., Avani, S., Gkini, C., Deilogkou, M., Koskinas, K., \& Alexias, G. (2017). Experiential Learning in Action: A Collaborative Inquiry. The Qualitative Report, 22(1), 271-288. https://doi.org/10.46743/2160-3715/2017.2551

Brailas, A., Koskinas, K., \& Alexias, G. (2016). Design and implementation of a web-based system to support collective reflective practice. International Journal of Designs for Learning, 73), 95-104. https://doi.org/10.14434/ijdl.v7i3.18864

Brailas, A., Koskinas, K., \& Alexias, G. (2017). Teaching to emerge: Toward a bottom-up pedagogy. Cogent Education, 4(1), 1377506. https://doi.org/10.1080/2331186X.2017.1377506

Brailas, A., \& Tsekeris, C. (2014). Social behaviour in the internet era: Cyborgs, adolescents and education. European Journal of Social Behaviour, 1(1), 1-4. https://doi.org/10.5281/zenodo.237023

Briant, K. J., Halter, A., Marchello, N., Escareño, M., \& Thompson, B. (2016). The Power of Digital Storytelling as a Culturally Relevant Health Promotion Tool. Health Promotion Practice, 17(6), 793-801. https://doi.org/10.1177/1524839916658023

Cahill, H., Coffey, J., \& Smith, K. (2016). Exploring embodied methodologies for transformative practice in early childhood and youth. Journal of Pedagogy, 7(1), 79-92. https://doi.org/10.1515/jped-2016-0005

Capra, F., \& Luisi, P. L. (2014). The Systems View of Life: A Unifying Vision. Cambridge University Press.

Carlson, T. D. (1997). Using art in narrative therapy: Enhancing therapeutic possibilities. The American Journal of Family Therapy, 25(3), 271-283. https://doi.org/10.1080/01926189708251072

Casares, D. R., \& Gladding, S. T. (2019). Using Comedy to Explore Racial-Ethnic Identity with Clients: A Narrative Approach. Journal of Creativity in Mental Health, 1-12. https://doi.org/10.1080/15401383.2019.1635937 
Clark, A. (2017). Seeing Real Life?: Working With the Visual to Understand Landscapes of Community. International Review of Qualitative Research, 10(2), 190-210. https://doi.org/10.1525/irqr.2017.10.2.190

Cormier, D. (2008). Rhizomatic Education: Community as Curriculum. Innovate: Journal of Online Education, 4(5), Article 2.

Dafermos, M. (2018). Developing Creativity in Science: The Case of Vygotsky. In M. Dafermos, Rethinking Cultural-Historical Theory (Vol. 4, pp. 215-242). Springer Singapore. https://doi.org/10.1007/978-981-13-0191-9_8

De Vecchi, N., Kenny, A., Dickson-Swift, V., \& Kidd, S. (2016). How digital storytelling is used in mental health: A scoping review: Digital Storytelling in Mental Health. International Journal of Mental Health Nursing, 25(3), 183-193. https://doi.org/10.1111/inm.12206

Deleuze, G., \& Guattari, F. (1987). A Thousand Plateaus: Capitalism and Schizophrenia. University of Minnesota Press.

Denzin, N. K. (2001). The reflexive interview and a performative social science. Qualitative Research, 1(1), 23-46. https://doi.org/10.1177/146879410100100102

Dickerson, V. (2016). What Is Narrative Therapy? Poststructural and Narrative Thinking in Family Therapy Practice. In V. Dickerson (Ed.), Poststructural and Narrative Thinking in Family Therapy (pp. 1-7). Springer International Publishing. https://doi.org/10.1007/978-3319-31490-7_1

East, L., Jackson, D., O'Brien, L., \& Peters, K. (2010). Storytelling: An approach that can help to develop resilience: Relating personal experiences can help participants to cope with their conditions and improve research, explain Leah East, Debra Jackson, Louise O'Brien and Kathleen Peters. Nurse Researcher, 17(3), 17-25. https://doi.org/10.7748/nr2010.04.17.3.17.c7742

Farrington, D. P., \& Ttofi, M. M. (2009). School-Based Programs to Reduce Bullying and Victimization. Campbel/ Systematic Reviews, 5(1). https://doi.org/10.4073/csr.2009.6

Fernandez, K. T. G., \& Lina, S. G. A. (2019). Draw Me Your Thoughts: The Use of Comic Strips as a Cognitive Behavioral Therapy Intervention. Journal of Creativity in Mental Health, 113. https://doi.org/10.1080/15401383.2019.1638861

Fokides, E. (2016). Using Autobiographical Digital Storytelling for the Integration of a Foreign Student in the School Environment. A Case Study. Journal of Information Technology Education: Innovations in Practice, 15, 099-115. https://doi.org/10.28945/3526

Fokides, E. (2017). Using Digital Storytelling to Inform Students About Bullying: Results of a Pilot Program: International Journal of Bias, Identity and Diversities in Education, 2(1), 2739. https://doi.org/10.4018/IJBIDE.2017010103 
Freidus, N., \& Hlubinka, M. (2002). Digital storytelling for reflective practice in communities of learners. ACM SIGGROUP Bulletin, 23(2), 24-26. https://doi.org/10.1145/962185.962195

Gachago, D., \& Livingston, C. (2020). The elephant in the room: Tensions between normative research and an ethics of care for digital storytelling in higher education. Reading $\&$ Writing, 11(1). https://doi.org/10.4102/rw.v11i1.242

Gleeson, K. (2011). Polytextual thematic analysis for visual data: Pinning down the analytic. In P. Reavey (Ed.), Visual Methods in Psychology: Using and Interpreting Image in Qualitative Research. Routledge Psychology Press.

Glesne, C., \& Pugach, M. C. (2018). Story as Pedagogy: A Reflective Commentary. LEARNing Landscapes, 11(2), 31-38. https://doi.org/10.36510/learnland.v11i2.943

Goleman, D., \& Senge, P. (2014). The Triple Focus: A New Approach to Education. More Than Sound Productions.

Gubrium, A., Fiddian-Green, A., Lowe, S., DiFulvio, G., \& Peterson, J. (2019). Digital storytelling as critical narrative intervention with adolescent women of Puerto Rican descent. Critical Public Health, 29(3), 290-301. https://doi.org/10.1080/09581596.2018.1451622

Guse, K., Spagat, A., Hill, A., Lira, A., Heathcock, S., \& Gilliam, M. (2013). Digital Storytelling: A Novel Methodology for Sexual Health Promotion. American Journal of Sexuality Education, 8(4), 213-227. https://doi.org/10.1080/15546128.2013.838504

Hessler, B., \& Lambert, J. (2017). Threshold concepts in digital storytelling: Naming what we know about storywork. In G. Jamissen, P. Hardy, Y. Nordkvelle, \& H. Pleasants (Eds.), Digital Storytelling in Higher Education (pp. 19-35). Springer International Publishing. https://doi.org/10.1007/978-3-319-51058-3

Holquist, M. (2002). Dialogism: Bakhtin and His World. Routledge.

Kearney, K. S., \& Hyle, A. E. (2004). Drawing out emotions: The use of participant-produced drawings in qualitative inquiry. Qualitative Research, 4(3), 361-382. https://doi.org/10.1177/1468794104047234

King, A. (1993). From Sage on the Stage to Guide on the Side. College Teaching, 41(1), 30-35. https://doi.org/10.1080/87567555.1993.9926781

Kress, G. (2010). Multimodality: A Social Semiotic Approach to Contemporary Communication. Routledge.

Leavy, P. (2015). Method Meets Art, Second Edition: Arts-Based Research Practice. Guilford Publications.

LeBlank, N., \& Irwin, R. (2018). Teachers Storying Themselves Into Teaching: Comics as an Emergent and Relational Form of Research. LEARNing Landscapes, 11(2), 223-239. 
Lessard, S., Caine, V., \& Clandinin, D. J. (2018). Exploring neglected narratives: Understanding vulnerability in narrative inquiry. Irish Educational Studies, 37(2), 191-204.

https://doi.org/10.1080/03323315.2018.1465835

Lester, L., Pearce, N., Waters, S., Barnes, A., Beatty, S., \& Cross, D. (2017). Family Involvement in a Whole-School Bullying Intervention: Mothers' and Fathers' Communication and Influence with Children. Journal of Child and Family Studies, 26(10), 2716-2727. https://doi.org/10.1007/s10826-017-0793-6

Lewin, K. (1946). Action Research and Minority Problems. Journal of Social Issues, 2(4), 34-46. https://doi.org/10.1111/j.1540-4560.1946.tb02295.x

Lichty, L. F., Kornbluh, M., Mortensen, J., \& Foster-Fishman, P. (2019). Claiming Online Space for Empowering Methods: Taking Photovoice to Scale Online. Global Journal of Community Psychology Practice, 10(3), 1-26.

Limper, R. (2000). Cooperation between parents, teachers, and school boards to prevent bullying in education: An overview of work done in the Netherlands. Aggressive Behavior, 26(1), 125-134. https://doi.org/10.1002/(SICI)1098-2337(2000)26:1<125::AID$A B 10>3.0 . C O ; 2-7$

Livesey, P. V., \& Runeson, G. (2018). Autoethnography and Theory Testing. Construction Economics and Building, 18(3), 40-54. https://doi.org/10.5130/AJCEB.v18i3.6139

Mannay, D. (2015). Visual, Narrative and Creative Research Methods: Application, reflection and ethics (1st ed.). Routledge. https://doi.org/10.4324/9781315775760

Matthews, N., \& Sunderland, N. (2017). Digital Storytelling in Health and Social Policy: Listening to Marginalised Voices. Taylor and Francis.

McAdam, E., \& Lang, P. (2003). Working in the Worlds of Children: Growing, Schools, Families, Communities Through Imagining. The International Journal of Narrative Therapy and Community Work, 2003, 48.

McAdam, E., \& Lang, P. (2009). Appreciative Work in Schools: Generating future communities. Kingsham Press.

O'Loughlin, M. (2016). A manifesto for critical narrative research and pedagogy for/with young children: Teacher and child as critical annalist. Journal of Pedagogy, 71), 11-24. https://doi.org/10.1515/jped-2016-0001

Olweus, D., \& Limber, S. P. (2010). Bullying in school: Evaluation and dissemination of the Olweus Bullying Prevention Program. American Journal of Orthopsychiatry, 80(1), 124-134. https://doi.org/10.1111/j.1939-0025.2010.01015.x 
Pechtelidis, Y., \& Kioupkiolis, A. (2020). Education as Commons, Children as Commoners: The Case Study of the Little Tree Community. Democracy and Education, 28(1), Article 5, 1-11. https://democracyeducationjournal.org/home/vol28/iss1/5

Pickering, A. (2017). The Ontological Turn: Taking Different Worlds Seriously. Social Analysis, 61(2). https://doi.org/10.3167/sa.2017.610209

Polychroni, K., Gournas, G., \& Sakkas, D. (2008). Actualizing Inner Voices and the Group Process: Experiential Training in Personal Development. Human Systems: The Journal of Therapy, Consultation \& Training, 19(1), 26-43.

Rana, L., \& Culbreath, Y. (2019). Culturally inclusive pedagogies of care: A narrative inquiry. Journal of Pedagogy, 10(2), 87-99. https://doi.org/10.2478/jped-2019-0008

Ricks, L., Kitchens, S., Goodrich, T., \& Hancock, E. (2014). My Story: The Use of Narrative Therapy in Individual and Group Counseling. Journal of Creativity in Mental Health, 9(1), 99-110. https://doi.org/10.1080/15401383.2013.870947

Sawyer, C. B., \& Willis, J. M. (2011). Introducing Digital Storytelling to Influence the Behavior of Children and Adolescents. Journal of Creativity in Mental Health, 6(4), 274-283. https://doi.org/10.1080/15401383.2011.630308

Sherman, B., \& Briggs, N. (2020). Language Learners as Digital Bricoleurs: Exploring Independent Learning in Individual Digital Ecologies. STEM Journal, 21(4), 83-106. https://doi.org/10.16875/STEM.2020.21.4.83

Silver, J. (2013). Visual methods. In C. Willig, Introducing Qualitative Research In Psychology. McGraw Hill Education, Open University Press.

Staley, B. (2018). Journeying Beyond: Digital Storytelling with Rural Youth. The Rural Educator, 38(2). https://doi.org/10.35608/ruraled.v38i2.225

Staley, B., \& Freeman, L. A. (2017). Digital storytelling as student-centred pedagogy: Empowering high school students to frame their futures. Research and Practice in Technology Enhanced Learning, 12(1), 21. https://doi.org/10.1186/s41039-017-0061-9

Stillman, J. R. (2016). How Narrative Therapy Principles Inform Practice for Therapists and Helping Professionals: Illustrated with Vignettes. In V. Dickerson (Ed.), Poststructural and Narrative Thinking in Family Therapy (pp. 83-97). Springer International Publishing. https://doi.org/10.1007/978-3-319-31490-7_6

Tham, J. (2015). Multimedia vs. Multimodal: A Matter of Terms [Blogpost]. Jason Tham Rhetoric • Technology • Communication. https://jasontham.com/2015/05/19/multimediavs-multimodal-a-matter-of-terms/

Thompson Long, B., \& Hall, T. (2018). Educational narrative inquiry through design-based research: Designing digital storytelling to make alternative knowledge visible and 
actionable. Irish Educational Studies, 37(2), 205-225.

https://doi.org/10.1080/03323315.2018.1465836

Thompson, S. (2014). Everybody's got a story: Examining the building of empathy and understanding for the bully, the bullied, and the bystander through digital storytelling [Thesis]. http://ir.library.dc-uoit.ca/handle/10155/422

Tomé, G., Almeida, A., Ramiro, L., Gaspar, T., \& Gaspar de Matos, M. (2021). Intervention in Schools promoting mental health and wellbeing: A systematic review. Global Journal of Community Psychology Practice, 12(1), 1-23.

Tsai, M.-K., Tseng, S.-S., \& Weng, J.-F. (2011). A Pilot Study of Interactive Storytelling for Bullying Prevention Education. In M. Chang, W.-Y. Hwang, M.-P. Chen, \& W. Müller (Eds.), Edutainment Technologies. Educational Games and Virtual Reality/Augmented Reality Applications (Vol. 6872, pp. 497-501). Springer Berlin Heidelberg. https://doi.org/10.1007/978-3-642-23456-9_89

Tzanavaris, S., Nikiforos, S., Mouratidis, D., \& Kermanidis, K. L. (2021). Virtual Learning Communities (VLCs) rethinking: From negotiation and conflict to prompting and inspiring. Education and Information Technologies, 26(1), 257-278. https://doi.org/10.1007/s10639020-10270-9

Vakali, E., \& Brailas, A. (2018). "Me and my students' smartphones in the classroom": A case study using arts-based methods. Homo Virtualis, 1(1), 35-52. https://doi.org/10.12681/homvir.19070

Vassiliou, G. A., \& Vassiliou, V. G. (1982). Outlining a Systemic-Dialectic Approach to Family Functioning and Malfunctioning. In M. Pines \& L. Rafaelsen (Eds.), The Individual and the Group (pp. 151-155). Springer US. https://doi.org/10.1007/978-1-4615-9239-6_15

Villarejo-Carballido, B., Pulido, C., de Botton, L., \& Serradell, O. (2019). Dialogic Model of Prevention and Resolution of Conflicts: Evidence of the Success of Cyberbullying Prevention in a Primary School in Catalonia. International Journal of Environmental Research and Public Health, 16(6), 918. https://doi.org/10.3390/ijerph16060918

White, M. (1993). Deconstruction and therapy. In S. Gilligan \& R. Price (Eds.), Therapeutic conversations (pp. 23-51). W W Norton \& Co.

White, M. (2007). Maps of narrative practice (1st ed). W.W. Norton \& Co. 